\title{
Should Zelen pre-randomised consent designs be used in some neonatal trials?
}

\author{
Peter Allmark Euricon and University of Sheffield, Sheffield
}

\begin{abstract}
My aim is to suggest that there is a case for using a randomised consent design in some neonatal trials. As an example I use the trials of extracorporeal membrane oxygenation (ECMO) in neonates suffering pulmonary hypertension.

In some trials the process of obtaining consent has the potential to harm the subject, for example, by disappointing those who end in the control group and by creating additional anxiety at times of acute illness. An example of such were the trials of extracorporeal membrane oxygenation (ECMO) in neonates suffering pulmonary hypertension.

Pre-randomised consent could avoid or lessen these harms. However, a number of ethical objections are made to these research designs. They involve denial of information, using people, denial of choice, and "overselling" of allocated treatment. Furthermore, they are the wrong response; better communication might be the answer, for example. I argue that these objections are not completely persuasive. However, they are enough to suggest caution in the use of such designs.

(Fournal of Medical Ethics 1999;25:325-329)
\end{abstract}

Keywords: Pre-randomisation; Zelen; neonatology; research; ECMO

\section{Introduction}

In a conventional randomised controlled trial (RCT) subjects are asked whether they wish to take part in the trial and, if they consent, are subsequently randomised to one of the treatment arms. In a Zelen pre-randomised consent design consent is sought after randomisation. There are two main types of Zelen design, single randomised consent (Z1) and double randomised consent (Z2).

$\mathrm{Z} 1$. In the single randomised consent design only subjects randomised to the new treatment arm are asked for consent to take part in the trial, those in the control group are simply treated with the standard treatment (with, at most, implied consent to that treatment). If those randomised to the new treatment refuse then they receive the standard treatment.
Z2. In the double randomised consent design subjects in both treatment arms are asked for consent to their allocated treatment. If they refuse then those allocated the new treatment receive the standard treatment instead, those allocated the standard treatment receive the new treatment.

Zelen first proposed the ( $\mathrm{Z} 1)$ design as a means of overcoming lack of recruitment to certain RCTs. However, neither design has been widely used explicitly. In 1990 Zelen published a paper outlining 11 trials which had used them. ${ }^{1}$ Two of these were trials of extracorporeal membrane oxygenation (ECMO) in neonates suffering pulmonary hypertension. ${ }^{2}$ However, the most important of the ECMO trials, the UK collaborative trial, ${ }^{3}$ did not use pre-randomised consent.

Pulmonary hypertension is a complex condition with varying causes and of varying severity. In neonates for whom ECMO was thought potentially worthwhile the UK collaborative trial has shown a $68 \%$ survival rate in the ECMO treatment arm, $41 \%$ in the conventional arm. This trial faced at least two particular ethical problems.

The first was whether the trial should have taken place at all. One concern was that the results of the two main earlier studies provided sufficient reason to undermine equipoise. ${ }^{4}$ Another concern was that it is unethical, where there is no effective alternative treatment, to restrict a potentially lifesaving treatment to a trial. ${ }^{5}$ (Although this hardly seems reasonable in the case of ECMO, where conventional therapy offered a $41 \%$ survival rate.) The basis of this suggestion is that such a restriction undermines the doctor-patient relationship as the doctor who enters a patient on such a study cannot be offering him or her what he thinks is the best treatment (as the patient might be randomised not to receive the potential life-saving treatment). My paper does not discuss these equipoise questions. I shall assume that for a RCT of whatever design to be ethical there should be equipoise.

The second was whether pre-randomisation might have been a preferable design for the trial. I am concerned in this paper with the second question, which I shall approach by asking: 
What were the problems with a conventional design in the trial of ECMO for which prerandomisation was the proposed solution?

Would pre-randomisation of either type overcome these problems?

What objections might there be to the use of prerandomisation?

\section{A. Problems with a conventional design in the trial of ECMO}

Neonatologists occasionally wish to research new interventions aimed at improving treatment of neonates in emergencies; ECMO was an example of this. In undertaking such trials it is normally expected that, where it is possible, the informed consent of parents will be sought. There are several potential problems with this, and ECMO faced many of them. Let us focus on those which pre-randomisation might be expected to help. Chief amongst these was the potential harm to parents whose consent was sought. There are at least three sources of potential harm ${ }^{6}$ :

H1: Distress at being asked to consider the complexities of randomisation and treatment when their child faces an emergency.

$\mathrm{H} 2$ : Distress at the realisation that their clinician, at a time they need to feel reassured by, and confident in her, does not know which treatment is best.

H3: Disappointment (in non-blinded RCTs) when, having consented to the trial, their neonate is randomised to the control group.

These could arise in a trial of ECMO for at least two reasons. First, because pulmonary hypertension is a rare illness which could not be foreseen prenatally, hence prenatal consent was thought impractical. Second, because ECMO is a treatment which involves attaching the neonate to special machinery. In the UK it usually involved transport to specialist centres as well. As such the trial of ECMO was unblinded to all, including parents. Parents were thus to be presented with a situation in which there was a high risk that their child would die with conventional therapy, and there was a new treatment whose effectiveness was unknown. Clearly for the trial to be ethical there must have been some form of equipoise. But it is not unlikely, given the fairly desperate nature of the situation, that parents would choose to be randomised hoping that their child would receive the new treatment which they believed must be better. Having decided to take part in the trial there was a $50 \%$ chance that the new treatment would be denied. It would hardly be surprising if parents then asked that their child receive ECMO anyway (as has been reported to me).
It might be objected that there is no evidence t $\frac{\vec{Q}}{\vec{Q}}$ suggest that full disclosure does cause distress? Thus there is no reason to stray from the conven tional design. This is not quite so. There has been one piece of qualitative research which intere viewed parents of surviving infants who had take part in the ECMO trial. ${ }^{8}$ Even though the interviews were only with parents whose babies had survived it is clear that the harms identifiee sometimes occurred. As well as this there is $\operatorname{som} \vec{e}$ anecdotal evidence. ${ }^{9}$ There is also, perhaps, an intuition that such harms are possible; one need to put oneself in the position of a parent who has

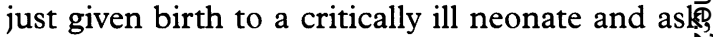
as Zelen does:

"Should the parents of a newborn infant, facing death, be advised of a clinical trial evaluating twer treatments for the infant's disease, one of whic $B$ will not be selected?" 10

There is some empirical work underway looking parents' experience of giving consent to neonata research which may offer some enlightenment. $\frac{11}{6}$ But the rest of my argument is plausible only t 89 those who accept the possibility of the harms outlined. Let us now turn to the second main question outlined in the introduction.

\section{B. Would pre-randomisation overcome these problems?}

Could pre-randomisation overcome any of these problems? Let us consider them in turn.

$\mathrm{H} 1$ : Much depends here on what it is felt the parents should know. With the $\mathrm{Z} 1$ design it seem that part of the point is that parents in the controg group would not be told they were in a triat, receiving only the information about the standare treatment which they would receive if they were not in a trial. Parents randomised to the new treatment appear to be pretty much in the sam position as before except that they know to whict treatment they have been allocated. This maf mean that there is no need to explain that it has been chosen randomly, only that it is different from the standard treatment. With the $\mathrm{Z} 2$ desig the key differences seem to be that parents know to which treatment they have been allocated and may not need to know it has been chose randomly.

H2: Again much will depend on what it is fe parents should know. Z1 parents in the contro should feel no anxiety over and above what the would feel in receiving the standard care anywa All other parents in $\mathrm{Z} 1$ and $\mathrm{Z} 2$ could feel the same anxiety about clinicians' uncertainty as parents a conventional trial. However, it is plausible that 
not knowing the random nature of selection reduces the appearance of uncertainty and hence of such anxiety.

H3: The Z1 design should certainly overcome this problem, parents in the control group will feel no disappointment because they are unaware of the alternative. It might be thought that $\mathrm{Z} 2$ should also overcome it, if parents in the control group do feel disappointment then they can opt for the new treatment instead. However, this depends on the parents having an option which was not available to parents in the conventional trial, that is, the option of choosing ECMO outside of the trial. This suggests that the $\mathrm{H} 3$ problem arises more because of the decision not to give parents this choice than from any fault in the conventional design itself. This is discussed further, below.

Overall it seems both forms of prerandomisation could aid overcoming the problems, $\mathrm{Z} 1$ being better than $\mathrm{Z} 2$ on this score. The two small trials of ECMO cited by Zelen which used pre-randomisation both used the $\mathrm{Z} 1$ design (for the randomised section of the trials). ${ }^{2}$ What objections might be raised to the use of prerandomisation?

\section{Objections to pre-randomisation}

Both statistical and ethical objections have been raised to pre-randomisation. ${ }^{12}$ Although the concern in this paper is with the ethics of prerandomisation, it is necessary to give a flavour of some statistical objections as these have implications for the ethical ones.

Essentially the statistical objections are that pre-randomisation is weaker than a conventional design. Unless no one refuses to participate in the trial then you have to recruit more subjects than a conventional design to get the same result. This problem worsens the more refusals you get. Hence: if $10 \%$ refuse then 390 recruits are required as against 250 on a conventional design: if $30 \%$ refuse this number rises to 1,560 ! The ethical significance of these statistical objections is that they put pressure on clinicians to keep the refusal rate down. Let us now consider the ethical objections in the light of this.

\section{Denial of information}

(i) In $\mathrm{Z} 1$ parents randomised to standard treatment are not told they are in a trial. A possible reply to this is that those in the standard group are effectively providing routine patient data. This is commonly done in epidemiological studies without informed consent. A lay person's idea of "being in a trial" is likely to involve trying out a new treatment, not receiving the usual one. Such an understanding does not seem unreasonable as long as no additional burdens (such as invasive tests) are imposed on the control group.

(ii) In $\mathrm{Z} 1$ parents randomised to standard treatment are not told of the alternative treatment. One possible reply to this is to say that there is not an alternative treatment because it is only available through the trial. This is not persuasive as the "non-availability" of the alternative treatment is down to fiat, the researchers have made it not available. More persuasive is the argument that there is no alternative treatment in the sense of one which is established, standard and proven.

(iii) No parents in such trials are told that their treatment has been chosen randomly. This is, of course, the basis for one of the positive effects of pre-randomisation, that parents do not need to understand and contemplate the difficult concept of randomisation, nor do they have their confidence in the clinicians undermined by thinking they don't know what to do. My belief is that it is morally inoffensive to deny this information to parents. If there is genuine clinician equipoise between treatments then they no more need to know that it was chosen randomly than they need to know that their particular doctor chooses one treatment on sunny days and the other on cloudy ones.

Against the denials of information outlined above must be put the fact that some participants in pre-randomised trials know to which treatment group they have been allocated before taking part, something denied to those in conventional trials.

\section{2. "Using people"}

Botros argues that the usual justification given for withholding information from patients, that it is in their best interest, does not hold for Zelen randomisation. ${ }^{13}$ Here withholding information is for the sake of the RCT, not for the sake of the patient. However, it will be remembered that the main ECMO trial was successfully completed using a conventional design. My argument has been that such a design could harm participants in the trial and that a Zelen design could avoid such harm. As such, the withholding of information the Zelen design involves is for the sake of the patient (parents) in the sort of case I have been discussing. It is possible to use Zelen randomisation simply to ease the research process for researchers, but this is not a use I would seek to justify.

\section{Denial of choice on the basis of the significance of non-clinical facts}

It was said earlier that parents allocated to the control group might feel disappointed. To the cli- 
nician, given that there is clinical equipoise, this may not seem a rational response as the new treatment might be better or worse. The problem is that parents may not share this equipoise. Given a high fatality rate and the chance of something better or worse a parent may well say, "To hell with the standard treatment, give me the new one". This does not seem desperately irrational, it seems rational in a desperate situation. The problem seems to arise in situations where there is a new treatment which, despite clinical equipoise, has non-clinical features which we know might make it preferable to some parents, or where the clinical situation is so bad anyway parents may want to "try anything".

In situations such as these $\mathrm{Z1}$ prerandomisation might be thought of as objectionable because it denies those in the control group an option they might wish to take. The argument that information should be denied to research volunteers in order to avoid distress is an extension of "a tired and discredited paternalism". ${ }^{14}$ Volunteers must be allowed to deliberate, choose and plan for the future. But in the conventional trial that option was denied anyway. If it was right to deny parents the choice of ECMO then the $\mathrm{Z} 1$ design would be preferable to the conventional design as it did not have the cruel attribute of making parents aware of what they were to be denied. If it was wrong to deny parents the choice of ECMO, then $\mathrm{Z} 1$ would be wrong. But then so was the conventional design which was used in the UK collaborative trial. Either a Z2 or conventional design offering the choice to choose a treatment outside the trial should have been used instead. ${ }^{15}$

How do we decide whether it was right or wrong to deny parents this choice? The answer may be similar to the one given regarding the permissibility of denying parents information about an alternative. That is, ECMO was not an alternative in the sense of being an established, standard, proven treatment. As such, clinicians were under no obligation to offer that choice. If this is so then the $\mathrm{Z} 1$ design appears the best choice.

\section{4. "Overselling" allocated treatment}

There is a strong temptation to "oversell" the allocated treatment. This problem is particularly acute given the statistical objections to prerandomisation. Thus, parents allocated to standard treatment are likely to have emphasised to them the dangers of the new treatment, those allocated the new treatment, the inadequacies of the standard. However, the fact that a design can be misused does not mean that it should not be used, only that it should be used with caution Furthermore, this problem may also exist in conf ventional trials. In such trials clinicians could begin by selling the possible benefits of the new treatment and then, having gained consent, mighit desperately "back-pedal" for those allocate standard treatment. ${ }^{16}$ Thus, whilst we shoulf beware this problem, it does not seem to me an overwhelming one. One way round it might be to ensure that information sheets given to parents are clear and fair.

\section{Pre-randomisation is the wrong response: I. Patient preference designs} There are other designs which solve the problem better. For example, the Bradley-Brewin designet enables participants to choose whether or not tor be randomised; if they choose not to be then the can choose which treatment they would prefer: This would overcome the harm $\mathrm{H} 3$, but would no overcome $\mathrm{H} 1$ or $\mathrm{H} 2$. As such, it is not obvious better than the Zelen designs. In the specific case of ECMO patient preference designs would facee another problem. ECMO was a limited resource It would simply not have been possible to offer to those in the control group.

\section{Pre-randomisation is the wrong response: II. Communication and choice} Whilst the harms outlined (H1-3) may indee⿳亠口冋 arise, it is not the fault of the conventional designt that they do. Rather, it is the fault of communic tion and/or of the decision to deny treatment choice to parents. For example, if parents are dis appointed at being allocated to the control grou then they have not been adequately informed that this could happen. Pre-randomisation "solves" problem of poor communication and limited choice by offering less communication and choice.$^{18}$ I have already argued that the decision to limit choice was probably justified in the case ECMO. I have also argued that the fact that treate ments about which there is equipoise are chosen randomly is not one of great import to the parents Telling parents in the control group of a treatmero which they have no chance of getting seems a unnecessary burden. Clearly, pre-randomisatiog should not be used simply to make life easy fo researchers, to avoid communication difficulties. But this must be for research ethics committees and their ilk to decide.

\section{Conclusion}

Almost all would agree that, other things being equal, one should seek consent from parents fof the involvement of their neonate in researck. 
However, other things are not always equal. Anecdotally and intuitively, it is possible that seeking parental consent in the ECMO trials could harm parents in at least three ways. Pre-randomisation would certainly avoid one of these (disappointment on being allocated to the standard treatment group), and may reduce the other two (distress at being asked to consider research complexities when the child faces an emergency, distress at the realisation of clinician uncertainty). $\mathrm{Zl}$ fares better than $\mathrm{Z} 2$ when it comes to reducing the latter two potential harms as those in the standard treatment group will certainly not suffer them. I believe that this is enough to suggest that the $\mathrm{Z1}$ design was worthy of consideration in the ECMO trials. Z2 was also worthy of consideration if it was not thought permissible to deny parents in the control group the choice of ECMO. However, there are a number of cautions to be made about pre-randomisation in general.

(i) Pre-randomisation involves a risk of "overselling" the allocated treatment. This is heightened by the fact that refusals to consent cause statistical problems for pre-randomisation. This is certainly a reason for caution in using these designs but does not, I suggest, undermine them completely.

(ii) One particular thing that should be cautioned against is the use of pre-randomisation in trials where clinicians are reluctant to broach the subject of an established alternative treatment which they believe subjects may have non-clinical reasons to prefer (for example mastectomy versus lumpectomy).

(iii) There is also a need to avoid the use of prerandomisation to get around communication problems which could be dealt with directly.

(iv) There may be other "alternative" designs worth considering. Like pre-randomisation, these may be statistically weaker than conventional designs but there sometimes has to be a balance between scientific rigour and ethical principle.

\section{Acknowledgements}

Thanks to John Platt, Geraint Duggan, Angela Todd, Dr Bryan Gill, Betty-Ann Muir and Dr Chris Megone for comments on earlier drafts. My thanks do not imply their endorsement of my argument.
Peter Allmark, $M A, R N, R N T$, is Research Administrator, Euricon and Nursing Lecturer, University of Sheffield. (Euricon is a multicentre European project asking whether informed consent to neonatal research trials is an elaborate ritual. It reports this year.)

\section{References}

1 Zelen M. Randomized consent designs for clinical trials: an update. Statistics in Medicine 1990;9:645-56.

2 O'Rourke P, Crone R, Vacanti J, Ware J, Lillihei C, Parad R, et al. A prospective randomized study of extracorporeal membrane oxygenation and conventional medical therapy in neonates with persistent pulmonary hypertension of the newborn. Pediatrics 1989;84:957-63; Bartlett R, Roloff D, Cornell R, Andrews A, Dillon P, Zwischenberger S. Extracorporeal circulation in neonatal respiratory failure: a prospective randomized trial. Pediatrics 1985;76:479-87.

3 UK Collaborative ECMO Trial Group. Extra-corporeal membrane oxygenation (ECMO): the UK collaborative neonatal ECMO trial. Lancet 1996;348:75-82. See also discussion in: Anonymous. Your baby is in a trial [editorial]. Lancet 1995;345: 805-6 and correspondence Lancet 1995;345:1370-1.

4 Burton P, Gurrin L, Hussey M. Interpreting the clinical trials of extracorporeal membrane oxygenation in the treatment of persistent pulmonary hypertension of the newborn. Seminars in Neonatology 1997;2:69-79.

5 Troug R. Randomized controlled trials: lessons from ECMO. Clinical Research 1992;40:519-27.

6 Tobias J. BMFs present policy (sometimes approving research in which patients have not given fully informed consent) is wholly correct. British Medical fournal 1997;314:1111-14; and: Tobias J. Fully informed consent can be needlessly cruel. British Medical fournal 1993;307:1 199-201.

7 Doyal L. Journals should not publish research to which patients have not given fully informed consent- with three exceptions. British Medical fournal 1997;314:1107-11; Emberton M, Wood C, Meredith P. Informed consent in clinical trials should be comprehensive [letter]. British Medical fournal 1993:307:1494.

8 Snowdon C, Garcia J, Elbourne D. Making sense of randomization; responses of parents of critically ill babies to random allocation of treatment in a clinical trial. Social Science in Medicine 1997;45:1337-55.

9 For example: Modi N. Informed consent difficult in paediatric intensive care [letter]. British Medical fournal 1993;307:1495; Eden O. Consent difficult in paediatric oncology [letter]. British Medical fournal 1994;308:272; Baum M. Reactionary approach inhibits progress [letter]. British Medical fournal 1994;308:271.

10 See reference $1: 648$.

11 The Euricon project, with which I am involved.

12 For example: Altman D, Whitehead J, Parmar M, Stenning S, Fayers P, Machin D. Randomised consent designs in cancer clinical trials. European fournal of Cancer 1995;31A:1934-44; Parmar M. Randomization before consent: practical and ethical considerations. In: Williams C, ed. Introducing new treatments for cancer: practical, ethical and legal problems. Chichester: Wiley, 1992:189-201. I take these statistical objections as given as the statistics itself is "beyond my ken".

13 Botros S. The ethics of randomised clinical trials. In Byrne J, ed. Ethics and law in health care research. Chichester: Wiley, 1990:9-24.

14 See reference 7: Doyal: 1108.

15 Although see the point concerning resource problems in the section on patient preference designs, below.

16 See reference 6: Tobias, (1997):1200.

17 Brewin C, Bradley C. Patient preferences and randomised clinical trials. British Medical fournal 1989;299:313-5.

18 Meran J. Ethics of consent for babies in randomised clinical trials. Lancet 1995;345:1370. 